\title{
Historical and Epistemological Reflections on the Culture of Machines around the Renaissance: Machines, Machineries and Perpetual Motion
}

\author{
Raffaele Pisano \\ Department of Physics \\ University of Lille1, \\ Bât. P5 bis, \\ Villeneuve d'Ascq F-59655, France \\ E-mail: pisanoraffaele@iol.it

\section{Paolo Bussotti} \\ Alexander von Humboldt Foundation, \\ Berlin, Germany \\ Via Paolo Lilla 66, \\ Livorno I-57122, Italy \\ E-mail:paolobussotti66@gmail.com
}

\begin{abstract}
This paper is the second part of our recent paper 'Historical and Epistemological Reflections on the Culture of Machines around the Renaissance: How Science and Technique Work' (Pisano \& Bussotti 2014a). In the first paper-which discussed some aspects of the relations between science and technology from Antiquity to the Renaissance-we highlighted the differences between the Aristotelian/Euclidean tradition and the Archimedean tradition. We also pointed out the way in which the two traditions were perceived around the Renaissance. The Archimedean tradition is connected with machines: its relationship with science and construction of machines should be made clear. It is enough to think that Archimedes mainly dealt with three machines: lever, pulley and screw (and a correlated principle of mechanical advantage). As underlined in the first part, our thesis is that many machines were constructed by people who ignored theory, even though, in other cases, the knowledge of the Archimedean tradition was a precious help in order to build machines. Hence, an a priori idea as to the relations between the Archimedean tradition and construction of machines cannot exist. In this second part we offer some examples of functioning machines constructed by people who ignored any physical theory, whereas, in other cases, the
\end{abstract}


ignorance of some principles-such as the impossibility of a perpetuum mobile -induced the attempt to construct impossible machines. What is very interesting is that these machines did not function, of course, as a perpetuum mobile, but anyway had their functioning and were useful for certain aims, although they were constructed on an idea which is completely wrong from a theoretical point of view. We mainly focus on the Renaissance and early modern period, but we also provide examples of machines built before and after this period. We have followed a chronological order in both parts, starting from the analysis of the situation in ancient Greece. Therefore, in the first part, we have examined the relations between the Aristotelian/Euclidean and Archimedean traditions from ancient Greece to the early modern age. In this second part, we analyse the relations of Archimedean tradition/ construction of machines from ancient Greece to the $19^{\text {th }}$ century, focusing on the mentioned period. We remind the reader that our aim is to prove an epistemological thesis, not to provide a complete historical endeavour.

As a correlated article, the reader will find three previous paragraphs in the first above-mentioned article (Pisano \& Bussotti, 2014a).

Keywords: foundations, machines, machineries, mechanics, perpetual motion, techniques

\section{Outline}

Our thesis in this paper is that science, technology and practical construction of machines have histories whose relations should not be given for granted. It is necessary to see case by case: in some cases — as a matter of fact, in many cases these histories are mutually independent. It can happen that some concepts were used in a correct manner by the constructors of machines, even though their theoretical definition and full comprehension was achieved many years after the construction of these machines, and the constructors had, of course, no theoretical idea of such concepts as abstract entities. Instead, in other cases, the lack of knowledge of some physical principles exerted a negative effect on the construction of machines because the men tried to construct impossible machineries. The case of machines which should have produced a perpetual motion is paradigmatic. The next two sections are dedicated to clarify our thesis with concrete examples. 


\section{On machines}

Generally speaking, the history of science studies only the successful applications of science to technology (Singer, 1954-1958; a more recent, very good source is Fox, 1995). However, the relations between science-technology are not uniform: it can happen that theoretical developments, which could be useful for technology, are exploited many years after their discovery and that, in contrast to this, some practical functioning instruments are constructed without a sufficient theoretical support. What about mechanics as a science and its relations with machine and machineries?

In ancient Greece, the term mechanics was used when referring to machines and devices in general. It was intended to mean the study of simple machines (winch, lever, pulley, wedge, screw ${ }^{1}$ and inclined plane $^{2}$ ) with reference to motive powers and displacements of bodies. Historically, works considering these arguments were referred to as Mechanics (from Aristotle, Heron, Pappus to Galileo). None of the treatises entitled Mechanics avoided theoretical considerations on its object, particularly on the lever law. The idea of a "simple machine" as a tool with mechanism-lever, pulley, and screw-has origin with Archimedes (287-212 BC). Later on, with Heron from Alexandria (fl. 10-75 AD), a question arose: What is the relationship between equilibrium, distance and work (positive andlor negative)? The answer can be found by means of the principle of virtual work law ${ }^{3}$ (displacements, velocities; Pisano, 2015b).

$1 \quad$ Which does apply the principle of an inclined plane but in a rotating motion. The screw is the only simple machine which offers the possibility to turn and drive inward.

2 See also the applications to the wedge. The idea of a simple machine originated with Archimedes who, as is well known, studied three machines: lever, pulley and screw. Later on, Heron of Alexandria (see Mechanica, in Heron 1899-1914, vol. II) studied five machines: winch, lever, pulley, wedge, and screw. Guidobaldo del Monte in Mecanicorum Liber (1577) supplied an advanced-for that period-theory of simple machines, also taking into account gravitas. He pointed out the limits of the approach held by the ancients to this subject, in particular as far as Aristotle's approach was concerned (Aristotle, 1955, pp. 329-411). Galilei in Le Mecaniche added the inclined plane, so that the number of simple machines became six.

3 In modern terms, to define the principle of virtual work, one can specify that a displacement is possible if it is compatible with the fixed constraints. Moreover, it is virtual if it is compatible with the constraints even though they are moving. Limiting ourselves to the case of time-independent constraints, we can also derive a possible displacement. In this discussion, the term displacement may refer to a translation or a rotation (and the term force to a force or a momentum). When the virtual quantities are independent variables, they are also arbitrary. 
Table 1. A physical-historiographical note on the principle of virtual works

The principle of virtual works is important both for theoretical physics and for the functioning of machines, but since our paper is not dedicated specifically to this principle, we prefer to provide some basic physical and historical notions on it in this table.

The principle of virtual work is a law of mechanics whose epistemological and ontological status is not yet generally shared: it can be seen both as a principle and as a theorem to be proven. The history and the physical features of the principle of virtual laws (velocities, work) state that this principle cannot simply be accepted as a self-evident truth, although it existed before all the laws of mechanics; by the way, there is not a general agreement on this subject among the scholars. Further, from a physicalmathematical point of view, the laws of mechanics can be derived by the principle. In other words, one cannot accept it as a mere principle (Pisano, 2015b). Therefore, either a proof, or a reduction to a theorem of another approach to mechanics, or an attempt to provide a more convincing version are necessary. Thus, the main problem with proving the principle of virtual work sparked a heated debate, especially in France where Lazare Carnot (1786; 1803a), Vittorio Fossombroni (1754-1844; 1794), Fourier (1878; 1888-1890, pp. 475-521), Ampère (1806) and Poinsot (1838; see also Poinsot, 1806) provided major contributions. In effect, a particular difficulty was linking the problem to Newtonian laws and obtaining its formal validity. Initially, this principle was independent from the Newtonian laws, which concerned an isolated particle (or the systems derived from it). The principle of virtual work also deals with extended systems of bodies, which, differently from Euler's reasoning on fluids (Euler, 1757, p. 286), include constraints in an essential way. The given forces are constraining reactions that are not included in the Newtonian scheme because they are unknown a priori (Lagrange, 1788, pt II, IV). It was to the principle of least action that the young Lagrange concentrated his attention. ${ }^{4}$

In modern terms, the principle is written:

$$
\delta W=\sum_{i} F_{i}^{(a)} \delta s_{i}=0 .
$$

For historical and epistemological recent historical accounts see Pisano, 2015b; Pisano \& Bussotti, 2015; Capechi, 2012. 
It follows the impossibility that the reactions of the constraints on the actions of the bodies, which make up the machine, produce positive work. Moreover, there were treatises which exhausted their role in proving this law; important among them are the Euclid's book on the balance and the already mentioned On the Equilibrium of Planes by Archimedes.

As we have seen in the first part of our paper, a Machine is a more or less complex apparatus (instrument and mechanism) consisting of one or more parts able to produce Work (positive, negative, null, mechanical equilibrium). The essential notions, such as, for example, force, power and motion are differently used in practical science and in theoretical science. We confirm: there are cases-and the one we have expounded concerning the Greek engineers and constructors is typical-in which a practical and implicit use of such notions exists which we could define as advanced, although in the Greek world there was no theoretical idea of such concepts which have been invented by the modern scientists. In this regard, Reuleaux (1876, p. 35) claims: "A machine as a combination of resistant bodies so arranged that by their means the mechanical forces of nature can be compelled to do work accompanied by certain determinant circumstances".

\section{On mechanics-machineries and perpetual motion}

Very fascinating from a historical point of view is the role played by perpetual motion in practical science (Angrist, 1968; Angrist \& Loren, 1967; Dircks, 1869; 1870 ), a kind of motion which is impossible (Capecchi \& Pisano, 2010b; Pisano $\&$ Bussotti, 2014a; 2014b; 2015). In this case, we will see that many scholars, engineers and constructors hoped to create a perpetuum mobile because they ignored that this is impossible.

Probably the first scientist who had the clear idea of the impossibility of a perpetuum mobile was Simon Stevin, who, among other assertions on this question, wrote: "It is not true [falsum] that the globe moves by itself with an endless movement [aeternum]". ${ }^{5}$

After Stevin, the principle of the impossibility of a perpetuum mobile became one of the bases of Leibniz's physics. He used these principles in many circumstances; the most famous one is, probably, the polemic against the Cartesians with regard

"[...] ipsique globi ex sese continuum et aeternum motum efficient, quod est falsum" (Stevin, [1605]1608, p 35). 
to the principles of conservation: quantity of motions, for Descartes and the Cartesians (Bussotti \& Pisano, 2013); vis viva for Leibniz. He also distinguished between a mechanical perpetuum mobile, which is impossible because such a machine should produce more energy than the initial one, and a physical perpetuum mobile, which is possible, at least theoretically, because the mechanism does not produce more energy than the initial one. This is the case of the pendulum, which, without friction, would continue to oscillate. ${ }^{6}$

In what follows, we will provide some examples of machines which were constructed to obtain the chimera of a perpetuum mobile. Obviously, they failed in this sense, but they were quite useful for other aims. These machines are examples which support our epistemological thesis based on historical evidences: it is possible to construct functioning and useful machines also ignoring some basic and fundamental principles, as that of the perpetuum mobile.

With regard to machines constructed to create an endless movement, a very attractive one was the magic wheel - a wheel spinning on its axle powered by lodestones, which appeared in eighth-century Bavaria. The wheel was supposed to rotate perpetually unless stopped by friction. Early designs of perpetual motion machines were done by Indian mathematician-astronomer Bhāskara II, who described a wheel (Bhäskara's wheel, Fig. 1a) which, he claimed, would run forever.

Leonardo da Vinci (1452-1519) also worked on perpetual motion machines:

- The paddleboat (Codex Atlanticus, 1487-1489, 945r). It is a project based on the use of engine. The external paddles are only outlined. Two pedals set the mechanism in motion that are linked to a belt creating a reciprocating motion. The mechanism transforms the reciprocating motion into a continuous rotary motion for the paddles. In the top right image (Fig.1b), the device is shown with a large flywheel.

- The swing bridge (Codex Atlanticus, 1487-1489, 885r). According to some historians, the swing bridge may have been one of the Leonardo's projects cited in the letter of self-recommendation to Ludovico the Moor. It is based on a complex system of winches and wheels, the bridge is made to rotate by $90^{\circ}$. This machinery allows boats to pass, or both banks of the canal to be cut off. To maintain the bridge's balance during the opening phase, and

$6 \quad$ The polemic against the Cartesians, the development of the concept of vis viva and the considerations on the impossibility of a perpetuum mobile are strictly connected in Leibniz. See, for example, Leibniz, 1686; [1860]1962, pp. 117-123; Leibniz, 1692?; [1860] 1962, pp. 215-231; Leibniz, 1695; [1860]1962, pp. 235-254, in particular, pp. 245-246. 
to prevent the whole structure giving way beneath its own forward weight, Leonardo provided a caisson full of stones to act as a counterbalance until the bridge came to rest on the opposite bank.

- The hydraulic saw (ca. 1500; Codex Atlanticus, 1487-1489, 1078r; Fig. 2). The wheel at the front is operated by a stream of running water. The waterpowered device activates a system of connecting rods that use reciprocating motion to work the saw at the top. At the same time, a winch slowly and gradually moves the carriage at the top, thus pushing the tree trunk or planks as they are sawn.

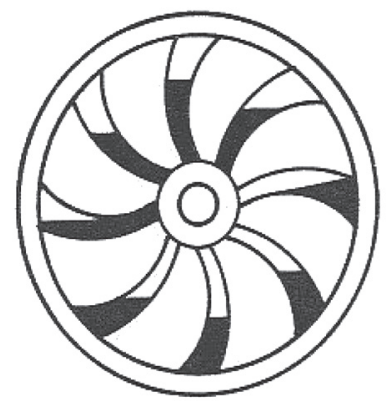

a. Bhaskara's wheel with curved spokes, ca. $12^{\text {th }}$ century. ${ }^{7}$

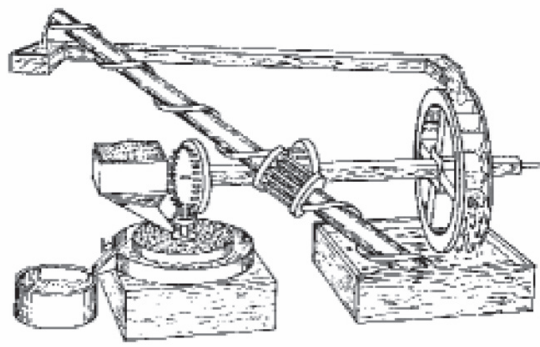

C. Recirculation mill 9 , $17^{\text {th }}$ century (Fludd, 1624).

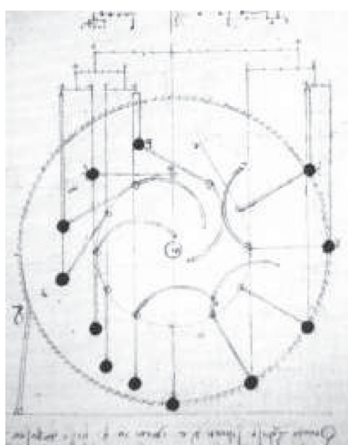

b. Leonardo's studies, impossibility of perpetual motion wheels-levers ${ }^{8}$, $15^{\text {th }}$ century.

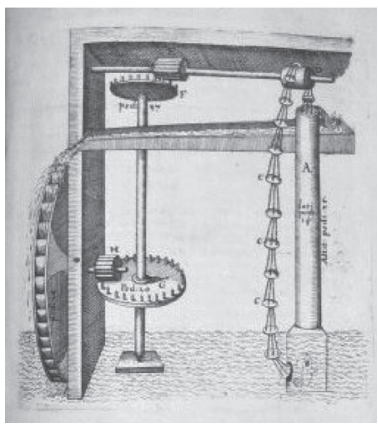

d. An Italian recirculation mill, $17^{\text {th }}$ century (Fludd, 1624).

Figure 1. Machines and chimera based on perpetual motion.

\footnotetext{
Also called overbalanced wheel (Dircks, 1870, p. 6).

8 Leonardo da Vinci, Codex Madrid, I, 145 r.

9 "Of another useful invention for raising water easily, by which a certain Italian ventured to boast that he had discovered a perpetual motion", Robert Fludd (1574-1673) in De Simia Naturae (1624).
} 


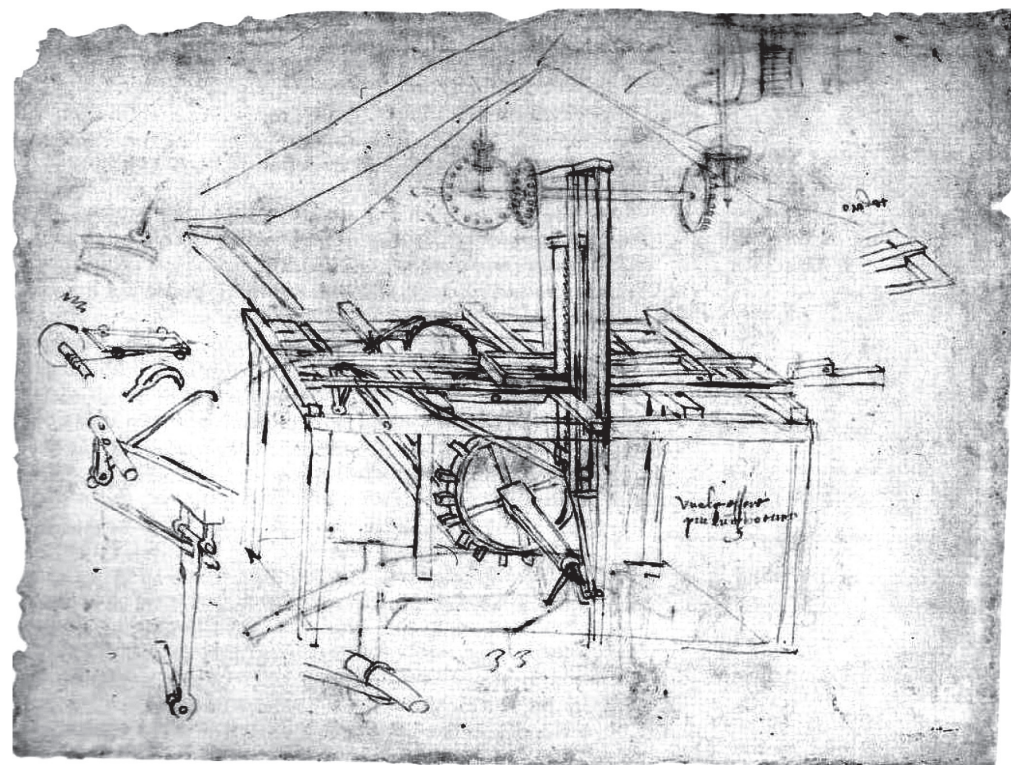

Figure 2. Leonardo's hydraulic saw ${ }^{10}, 15^{\text {th }}$ century.

In addition, perpetual motion machines were devised by:

- de Honnecourt (fl. $13^{\text {th }}$ century), perpetual motion on mechanics and architecture $^{11}, 13^{\text {th }}$ century;

- Zimara proposed a self-blowing windmill, $16^{\text {th }}$ century (Tallmadge, 1941, pp. 8-14);

- Boyle devised the perpetual vase, that is, perpetual goblet or hydrostatic paradox ${ }^{12}$, $16^{\text {th }}$ century.

Particularly important inventions were:

- Böckler designed a self-operating self-powered water mill and several perpetual motion machines using balls. These are variants of Archimedes' screws, $17^{\text {th }}$ century (Böckler, 1661; see also Dircks, 1870, pp. 36-42);

- Bernoulli proposed a fluid energy machine, $18^{\text {th }}$ century (Dircks, 1870, pp. 59-62, pp. 163-165; Ord-Hume, 1977).

10 Leonardo da Vinci (ca. 1478), on the left: Codex Atlanticus, 1487-1489, 1078r. Another interesting hydraulic machine is cafango (see Institute de France Manuscripts (1513-1514), Ms E, f 75v, in Pisano, 2013).

11 Le carnet de Villard de Honnecourt, ca. 1230. 5r, see also Pisano \& Bussotti, 2014b; Capecchi \& Pisano, 2010a.

12 On this, see the interesting presentation in Papin's Observation on a French Paper, concerning a perpetual motion (Papin, 1685, pp. 240-241). 


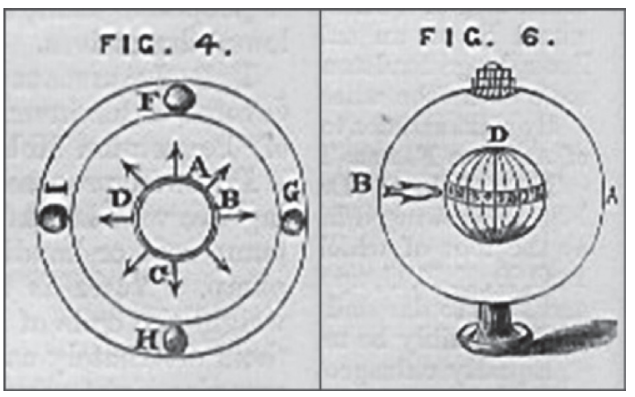

a. Kircher's wheel-sphere ${ }^{13}$,

$17^{\text {th }}$ century.

b. Kircher's water cycle ${ }^{14}$, $17^{\text {th }}$ century.

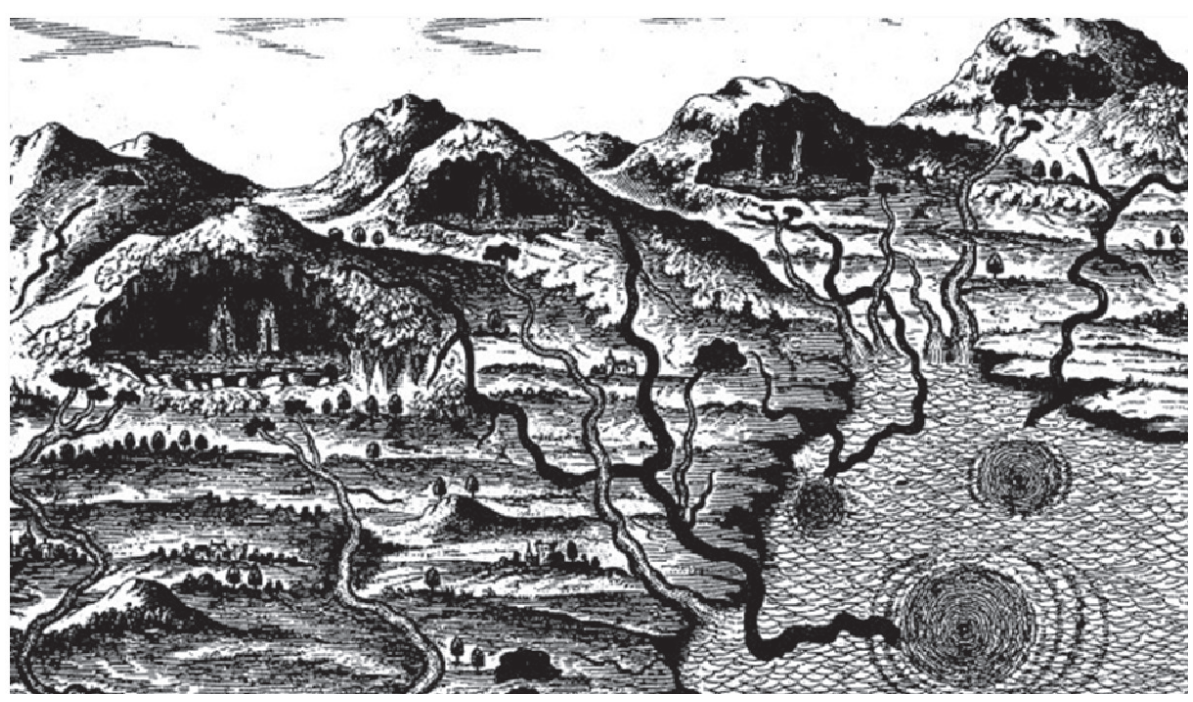

Figure 3. Perpetual cycles.

Thus, a machine can be, more or less, imperfect. The impossibility of perpetual motion represents its innate imperfection:

In the work [Carnot L 1786] whose analysis has carried me farther than I expected, Carnot has devoted some lines to the question of perpetual motion! He shows not only that every machine, of whatever form, abandoned to itself will stop, but he moreover assigns the moment at which that must happen. The arguments of our colleague are excellent; no geometer will dispute their exactness; may we yet hope that they will nip in the bud the numerous

13 The water wheel driving a force pump to lift water to the top of the wheel, magnetic spheres and wheels turning continually in response to fixed magnets.

14 The water is sucked down whirlpools in lakes, passes through fissures in rock and by capillary action rises to the topes of mountains where it gushes forth in springs. These springs are the source of mountain streams, which in turn feed the lakes. 


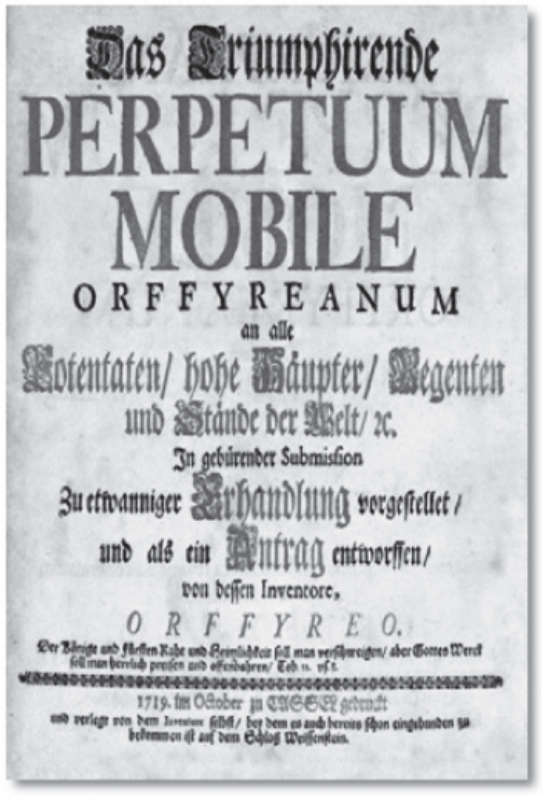

a. Perpetuum mobile (Bessler, 1719). From the Library of Max Planck Institute for the History of Science.

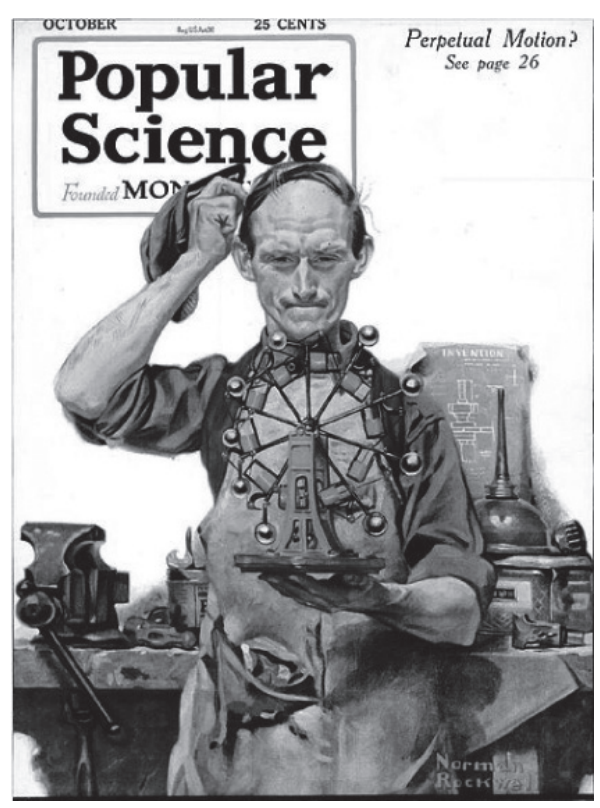

b. Rockwell's Perpetual Motion, 1920.

Figure 4. Perpetual motion and popular science.

projects which every year, or rather "every spring," sees burst into flower? This is what we cannot hope for. ${ }^{15}$

\section{On physical principles}

The theoretical science does not study machines in themselves, rather the general and abstract notions. It is then necessary to evaluate the possibility to adapt these notions to machineries and machines, taking into account that they are not ideal and perfect objects, but real and imperfect ones. Therefore, relying on the above-cited Reuleaux's definition, one can add that a Machine is an a apparatus, which is more or less complex (instruments and mechanism), consisting of one or more parts able to produce Work (positive, negative, null, mechanical equilibrium).

15 Arago, 1857, p. 29. See Dircks' comments (Dircks, 1870, pp. 142-143) and Carnot's words (Carnot, 1803, p. 256). On Carnot's science see Gillispie \& Pisano, 2014; Pisano, 2015. 
It can be a mechanical, chemical, thermal, electrical, etc. work, which is related to various applied sciences. From a physical point of view, we can ask: What is the relationship between equilibrium, distance and work (positive andlor negative)? Which is the practical role of the principle of virtual work laws (displacements, velocities)? Since a machine may be also thought as a device that helps to make work easier to perform by accomplishing one or more of the following functions:

- Transferring a force from one place to another;

- Changing the direction of a force;

- Increasing the magnitude of a force; or

- Increasing the distance or effect of a force.

Nevertheless, it is also useful to think of a machine in terms of the input force (the force you apply) and the output force (the force that is applied to the task). Therefore, when a machine takes a small input force and increases the magnitude of the output force, a mechanical advantage has been produced. What kind of theoretical relationship can be drawn between applied force, machinery and motion?

For example, the theory concerning resistance of beams was (essentially) founded on two basic (theoretical and practical) assumptions of geometry and mechanics already used in the Renaissance (Knobloch, 2002; 2005; Knobloch, Vasoli \& Siraisi, 2001), though still embryonic from a scientific point of view:

- A geometrical assumption that permitted to study the breaking mechanism;

- A mechanical assumption that concerned the ways of breakage of bodies, involving also the physical nature of matter.

However, we also know that utility had traditionally not held any place in theoretical science, only in the arts and crafts. On the other hand, technology had many successes in the course of history without any assistance from science. ${ }^{16}$

A scientific argument may be the mechanical advantage within machineries problems: a simple ratio of output force divided by input force. If the output force is bigger than the input force, a machine has a mechanical advantage greater than one. Let us give an example: if a machine increases an input power (force?) of 10 pounds to an output power (force?) of 100 pounds, the machine has a mechanical advantage of 10 . In machines that increase distance instead of force, the mechanical advantage is the ratio of the output distance and input distance. Thus mechanical advantage is an output/input depending

16 One can think that the physics by Aristotelian school was designed to explain the causes of things, not to be used by the engineers, the architects or builders. 
on machine's geometry without focusing on the physical quantities; that is, no measurements were necessary. On the other hand, from the physical standpoint, it was not possible to build a machine that increases both the physical quantity and the physical distance of a given "force" at the same time because this is equivalent to constructing a perpetuum mobile.

In this way we see that the construction of a machine based on conscious scientific methods should include, at least, three kinds of considerations:

1) The geometry of the machine;

2) The physical principles;

3) The practical skill of the constructors.

As a matter of fact, we have seen that in many cases the machines were constructed relying on the third consideration. A boundary divides machines and particular functions (machinery) of particular built machines (crafts).

\section{Concluding remarks ${ }^{17}$}

Let us conclude with a question and an answer:

\section{No theory-no machine?}

The answer is no: functioning machines can be constructed without any theory. This is certainly true for machines constructed in the long period preceding the $16^{\text {th }}-17^{\text {th }}$ centuries, in which no theory applicable to machines existed, if we exclude the case of the lever. However, in the following period, too, many machines were constructed independently of a theoretical support. This depends on two facts, which have to be taken into account:

- As to lever and connected machines: the weights can be used in a correct manner without knowing the difference between weight and mass and without having a precise idea of what a force is;

- As to hydraulic machines: the concept of water flow, velocity and the crucial relationships between these quantities and their relative proportions run, without scientifically knowing the relations between $V, A, v$.

${ }_{17}$ The concluding remarks are valid for the first correlated article as well. 
Anyway, it is remarkable that many functioning machines were constructed on the basis of wrong physical ideas as that concerning the existence of a perpetuum mobile, which confirms our thesis that working machines can be based on wrong physical principles, at least to a certain extent.

On the other hand, we do not want to provide a too simplified picture: there are some relations between science, technique and machine-constructions. We have analyzed a part of Archimedes' work because it is also connected to practical science. Archimedes' studies on the barycenters (Capecchi \& Pisano, 2007) and on the equilibrium of planes can be interpreted in a theoretical manner: that is, as studies deriving from the mathematical and physical-theoretical interests of Archimedes. However, they were produced in the context of the Hellenistic civilization, which-for that time-had a high technological level; they were hence inserted in an environment in which the studies on the machines were beginning to become important from a social and economic point of view. Let us then consider the situation in the Renaissance period and in the $17^{\text {th }}$ century: the studies on the projectiles or the magnificent researches by Galilei on the resistance of the materials, in which he proved that the resistance of a structure is not invariable by similarities but that - given the same form-a bigger structure is less resistant than one smaller (Galilei, [1638]1898, Day II), are probably connected to the general situation of that period. For, it is well known that, starting from the $16^{\text {th }}$ century, the necessity to have a more precise idea of the relations between the dimensions and the forms of a machine became unavoidable.

In the perspective of a study concerning the relationships between the development of theoretical science and the constructions of machine in the Renaissance and in the early modern age, we are carrying out a series of researches on the resistance of materials and on the development of the machine parts (gears, inclined planes, vertical-horizontal mill paddles and so on). Among other outputs, we aim at reconstructing the methods used to measure the physical quantities useful for the construction and functioning of machines. We are going to check which were the mathematical models used to determine the physical relationships among quantities as friction and motive power. More in general: What are the relations between the theoretical results in physics and the culture of machines?

We can summarize the relations between theoretical mechanics and the culture of machines by means of the following diagrams (Figs. $5 \& 6$ ): 


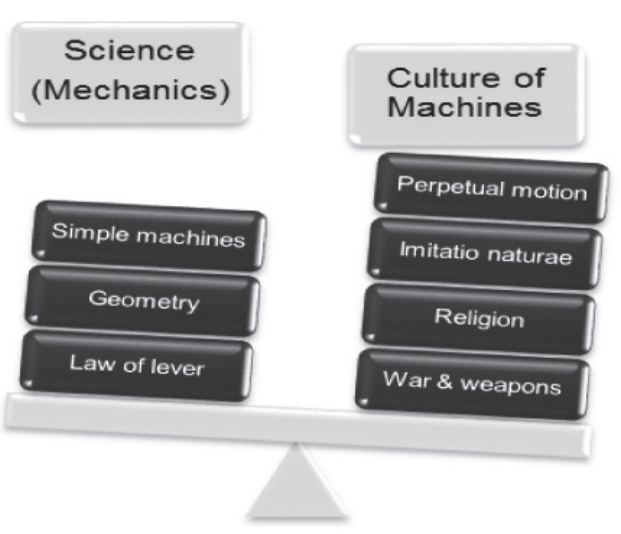

Figure 5. The "heavies" of Cultures.

Finally, by considering complex aspects that, for sake of brevity, we can summarize:

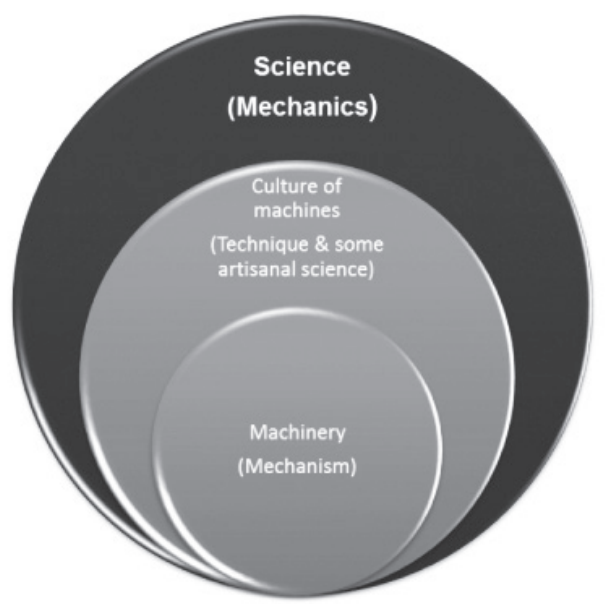

Mechanics (maths \& physics \& geometry) as the final result of the gathering between machinery and machines. So that mechanics includes the culture of machines-technique, which includes machinery. This is the theoretical perspective which does not correspond to the historical development.

Figure 6. A historical epistemological interpretation.

Thus, we can conclude that there is no continuity in the relations mechanicsculture of machines-machinery and the one we propose can be a new perspective in the studies concerning the relations mechanics-culture of machines-machinery. 


\section{Acknowledgments}

We want to express our gratitude to anonymous referees for precious comments and helpful suggestions.

\section{References $^{18}$}

Ampère, A. M. (1806), 'Démonstration du principe des vitesses virtuelles, dégagée de toute considération des infiniment petits', Journal de l'École Polytechnique, vol. 6, no. 13, pp. 247-269.

Angrist, S. W. (1968), 'Perpetual Motion Machines', Scientific American, vol. 2018, no. 1, pp. 114-122. http://dx.doi.org/10.1038/scientificamerican0168-114

Angrist, S. W. \& Loren, G. H. (1967), Order and Chaos, Oxford: Basic Books. PMCid:PMC2093767

Arago, F. (1857), Biographies of Distinguished Scientific Men, transl. by W. H. Smyth, B. Powell and R. Grant, London: Longman, Brown, Green, Longmans, \& Roberts.

Archimedes (1881), Opera Omnia cum commentari Eutocii, Heiberg JL (ed), Lipsiae: Teubneri BG.

([1897]2002), On the Equilibrium of Planes, in T. Heath (ed.) The Works of Archimedes, New York: Dover Publications Inc., pp. 189-220.

Aristotle (1955), Problemata Mechanica, in Aristotle, Minor Works, transl. by W. S. Hett, London: Heinemann \& Cambridge, MA: The Harvard University Press, pp. 329-411.

Bessler, J. E. E. (1719), Triumphans perpetuum mobile Orffyreanum: [...] gebuerender Submission zu etwanniger Erhandlung vorgestellet und als ein Antrag entworffen [entworfen], Inventore, Orffyreo, Selbstverlag.

Böckler, G. A. (1661), Theatrum Machinarum Novum, Nürnberg: Christoff Gerhard für Paul Fürst.

Bussotti, P. \& Pisano, R. (2013), 'On the Conceptual Frames in René Descartes' Physical Works,' Advances in Historical Studies, no. 2(3), pp. 106-125. http://dx.doi.org/10.4236/ahs.2013.23015

Capecchi, D. (2012), History of Virtual Work Laws, Milano: Birkhäuser. http://dx.doi.org/10.1007/978-88-470-2056-6

Capecchi, D. \& Pisano, R. (2007), 'Torricelli e la teoria dei baricentri come fondamento della statica,' Physis, no. XLIV, pp. 1-29. (2010a), Scienza e tecnica nell'architettura del Rinascimento, Roma: CISU.

18 Please also see the list of references in Pisano \& Bussotti, 2014a. 
Raffaele Pisano

Paolo Bussotti

(2010b), 'Reflections on Torricelli's principle in mechanics,' Organon, no. 42, pp. 81-98.

Carnot, L. (1786), Essai sur les machines en general, Dijon: Defay. (1803), Principes fondamentaux de l'équilibre et du movement, Paris: Deterville.

Leonardo da Vinci (1940), I libri di meccanica nella ricostruzione ordinata di Arturo Uccelli preceduti da una introduzione critica e da un esame delle fonti, Milano: Hoepli.

Del Monte, G. (1577), Mechanicorum Liber, Pisauri: Hieronymum Concordiam.

Dircks, H. (1869), Scientific Studies or Practical, in Contrast With Chimerical Pursuits, Exemplified in Two Popular Lectures. I. The Life of Edward Somerset, Second Marquis of Worcester, Inventor of the Steam Engine. II. Chimeras of Science: Astrology, Alchemy, Squaring the Circle, Perpetuum Mobile, Etc, London: Spon.

(1870), Perpetuum Mobile, or the history of the search for self-motive power from the $13^{\text {th }}$ to the $19^{\text {th }}$ century, London: Spon.

(1916), Perpetuum Mobile, or the search for self-motive power during the $17^{\text {th }}, 18^{\text {th }}$ and $19^{\text {th }}$ centuries, Chicago: Rogers and Hall Co.

Euler, L. (1757), 'Principes généraux du mouvement des fluides,' Mémoires de l'Académie des Sciences de Berlin, vol. 11, pp. 274-315.

Fludd, R. (1624), Tractatus secundus de naturae simia seu technica macrocosmi historia, Frankfort: For the heirs of J. T. de Bry, by C. Rotelius.

Fossombroni, V. (1794), Memoria sul principio delle velocità virtuali, Firenze: Gaetano Cambiagi.

Fourier, J. B. J. (1878), Analytical theory of heat, Transl. by Freeman A, London: The Cambridge University Press.

_ (1888-1890), Euvres de Fourier par les soins de M. Gaston Darboux, 2 vols., Paris: Gauthier-Villars.

Fox, R. (1995), 'Science, Industry and the Social Order in Post-Revolutionary France,' Variorum Collected Studies Series 489, Aldershot \& Brookfield: Ashgate Variorum.

Galilei, G. ([1599?]1634), Le Mecaniche, in A. Favaro (ed.) Edizione Nazionale delle Opere di Galileo Galilei, vol. II, pp. 149-191, Barbèra: Firenze.

([1638]1898), Discorsi e dimostrazioni matematiche intorno a due nuove scienze, in A. Favaro (ed.) Edizione Nazionale delle Opere di Galileo Galilei, vol. VIII, Barbèra: Firenze.

Gillispie, C. C. \& Pisano, R. (2014), Lazare and Sadi Carnot: A Scientific and Filial Relationship, $2^{\text {nd }}$ ed., Dordrecht: Springer. http://dx.doi.org/10.1007/978-94-0178011-7.

Heath, T. L., ed. (2002), The Works of Archimedes, New York: Dover Publications Inc.

Heron (1899-1914), Heronis Alexandrini Opera quae supersunt omnia, 5 vols., Leipzig: Teubner.

Knobloch, E. (2002), 'Les ingénieurs de la Renaissance et leurs manuscrits et traités 
illustrés,' in M. C. Duffy (ed.) Engineers and Engineering. Proceedings of the XXth International Congress of History of Science, Liège, 20-26 July 1997 (De diversis artibus tome 60 (N.S. 23)), Turnhout: Brepols, pp. 23-65.

- (2005), 'Géométrie pratique, Géométrie savant,' Albertiana, no. 8, pp. 27-56

Knobloch, E.; Vasoli, C. \& Siraisi, N. (2001), Il Rinascimento, in Medioevo, Rinascimento. Storia della scienza, vol. IV, Roma: Istituto della Enciclopedia Italiana, pp. 605-1044.

Lagrange, J. L. (1788), Mécanique Analytique, Paris: Desaint.

Leibniz, G. W. (1686), 'Brevis Demonstratio Erroris memorabilis Cartesii et aliorum circa Legem naturalem, secundum quam volunt a deo eandem semper quantitatem motus conservari, qua et in re mechanica abutuntur' plus Beilage, in G. W. Leibniz ([1860]1962), Mathematische Schriften, vol. VI, Hildesheim: Georg Olms, pp. 117-123.

(1692?), 'Essay de Dynamique sur les loix du mouvement, où il est monstré, qu'il ne se conserve pas la même Quantité du mouvement, mais la même Force absolute, ou bien la même Quantité de l'Action motrix,' in G. W. Leibniz ([1860]1962), Mathematische Schriften, vol. VI, Hildesheim: Georg Olms, pp. 215-231.

(1695), 'Specimen dynamicum pro admirandis Naturae legibus circa corporum vires et mutuas actiones detegendis et ad suas causas revocandis,' Part I and II, in G. W. Leibniz ([1860]1962), Mathematische Schriften, vol. VI, Hildesheim: Georg Olms, pp. 235-254.

_ ([1860]1962), Mathematische Schriften, vol. VI, ed. by C. L. Gerhardt, Hildesheim: Georg Olms.

Ord-Hume, A. W. J. G. (1977), Perpetual Motion, the History of an Obsession, New York: St. Martin's Press.

Papin, D. (1685), 'Observation on a French Paper, concerning a perpetual motion,' in C. Hutton, G. Shaw \& R. Pearson (eds.) The Philosophical Transaction of the Royal Society of London From [...] 1665 to [...] 1800, London: Baldwin C and Baldwin R, pp. 240-241.

Pisano, R. (2013), 'Reflections on the Scientific Conceptual Streams in Leonardo da Vinci and his Relationship with Luca Pacioli,' Advances in Historical Studies, vol. 2, no. 2, pp. 32-45. http://dx.doi.org/10.4236/ahs.2013.22007

—_ ed. (2015a), A Bridge between Conceptual Frameworks, Science, Society and Technology Studies, Dordrecht: Springer.

(2015b, forthcoming), A Development of the Principle of Virtual Laws and its Framework in Lazare Carnot's Mechanics as Manifest Relationship between Physics and Mathematics. Submitted to Foundations of Physics.

Pisano, R. \& Bussotti, P. (2014a), 'Historical and Epistemological Reflections on the Culture of Machines around the Renaissance: How Science and Technique Work?' Acta Baltica Historiae et Philosophiae Scientiarum, vol. 2, no. 2, pp. 20-42. http://dx.doi.org/10.11590/abhps.2014.2.02 
(2014b), 'Notes on mechanics and mathematics in Torricelli as physics mathematics relationships in the history of science,' Problems of Education in the $21^{\text {st }}$ Century, vol. 61, no. 61, pp. 88-97.

(2015), 'The Emergencies of Mechanics and Thermodynamics in the Western Society during $18^{\text {th }}-19^{\text {th }}$ Century', in R. Pisano (ed.) A Bridge between Conceptual Frameworks, Science, Society and Technology Studies, Dordrecht: Springer.

Poinsot, L. (1806), 'La Théorie générale de l'équilibre et du mouvement des systems,' Journal de l'École Polytechnique, vol. 6, no. 13, pp. 206-241.

(1838), 'Note sur une certaine démonstration du principe des vitesses virtuelles, qu'on trouve au chapitre III de livre 1er de la "Mécanique céleste", Journal de mathématiques pures et appliqués, vol. 1, no. 3, pp. 244-248.

Reuleaux, F. (1876), Kinematics of Machinery: Outlines of Theory of Machines, London: Macmillan \& Co.

Singer, C. (1954-1958), A History of technology, vols. 2-4, Oxford: The Clarendon Press.

Stevin, S. (1605), Tomus quartum mathematicorum hypomnematum de statica, Lugodini Batavorum: Ioannis Patii.

Tallmadge, G. K. (1941), 'The Perpetual Motion Machine of Mark Antony Zimara,' Isis, vol. 33, no. 1, pp. 8-14. http://dx.doi.org/10.1086/358520

Raffaele Pisano (Italy, 1970) earned his master's degree in physics and then specialized education in physics and mathematics at the University Federico II, Napoli, Italy; PHD at the University of Roma La Sapienza. He is qualified in history of physics, history and epistemology of science, logics \& philosophy, physics-fundamental interaction and is lecturer-researcher in history and epistemology of science, science \& society studies at the University of Lille1, France. Since 2011, he acts as vice president of the InterDivisional Teaching Commission (DLMPS/IUHST). He is former head of the Research Centre for the Theory and History of Science, University of West Bohemia in Pilsen, Czech Republic. Pisano has authored more than one hundred publications (books and journals). The most recent publications are: Lazare and Sadi Carnot. A Scientific and Filial Relationship (2014, $2^{\text {nd }}$ ed., Dordrecht: Springer) with Charles Coulston Gillispie; The Dialectic Relation between Physics and Mathematics in the XIX ${ }^{\text {th }}$ Century (2013, Dordrecht: Springer), co-edited with Evelyne Barbin. Forthcoming publications include: Tartaglia's Science of Weights and Mechanics in Sixteenth Century. Selections from Quesiti et inventioni diverse: Books VII-VIII (Dordrecht: Springer) with Danilo Capecchi; Newton's Principia "Jesuit" Edition: The Tenor of a Huge Work, Accademia Nazionale Lincei-Rendiconti Matematica e Applicazioni 
2014, vol. 25, pp. 1-32 with Paolo Bussotti). More info at fr.linkedin.com/ pub/raffaele-pisano/6/a11/a61/

Paolo Bussotti received his PHD degree in history of science from San Marino University in 1996. He got an Alexander von Humboldt fellowship in 2003-2005 at the Ludwig-Maximilians-Universität, Munich, to work on the history of number theory. He has also worked for the Kepler Kommission, Bavarian Academy of Sciences, Munich. In 2008-2010, he was director of the Centro Studi Enriques, Livorno, Italy. Recently he spent a period as visiting lecturer at the Research Centre for the Theory and History of Science, Dept. of Philosophy and Science Education, West Bohemia University, Pilsen, Czech Republic. He also got an Alexander von Humboldt fellowship at the Berlin Academy of Sciences to work on Leibniz's planetary theory. Research fields: history and philosophy of science and mathematics, particularly the period 1500-1800, and mathematics. 